\title{
Estudo Sociométrico de uma Instituição Alternativa para Crianças e Adolescentes em Situação de Rua: Construindo uma Proposta Pedagógica
}

\author{
Maria Inês Gandolfo Conceição ${ }^{1}$ \\ Maria Fátima Olivier Sudbrack. \\ Universidade de Brasilia
}

\begin{abstract}
Resumo
Trata-se de investigação sobre uma instituição de atendimento a adolescentes em situação de rua, escolhida pelo fato de os atrair e retirar da marginalidade. O objetivo foi identificar os principais elementos da instituição responsáveis pela fixação e adesão da clientela, visando oferecer subsídios para a construção de propostas pedagógicas de atendimento a meninos de rua. A coleta de dados consistiu na aplicação do teste sociométrico da instituição e em entrevistas individuais com seus membros. A análise dos dados fundamentouse na Teoria Sociométrica com contribuições da abordagem familiar sistêmica. Os aspectos relevantes para a efetividade do trabalho com meninos de rua foram: a) escolha sociométrica como critério de seleção da clientela; b) afinidade e integração entre os dirigentes da instituição; c) consonância entre a oferta da instituição e a demanda da clientela de "viverem em família"; d) presença de uma figura masculina positiva e forte de autoridade, identificada como "o pai".

Palavras-chave: Crianças em situação de rua; estudo sociométrico; instituição.
\end{abstract}

Sociometric Study of an Alternative Institution for Street Children: Building a Pedagogic Proposal

\begin{abstract}
This is a research of an institution which provides assistance to homeless children which was chosen because it got the children's attention and took them out of the marginality. The research aims at identifying the elements that are mainly responsible for the adherence and maintenance of the clientele to the institution project. The data was complied by means of a sociometric test of the institution and by individual interviews with their members. The analysis of the data was based on the Sociometric Theory and the Systemic Theory contributions. The relevant aspects for an effective work with homeless children were: a) sociometric choice as a selection criteria; b) affinity and integration among the directors of the institution; c) consonance between the institution offering and the children demand "to live in a family environment"; d) presence of a male figure with positive personality and strong authority identified as "the father".

Keywords: Homeless children; sociometric study; institution.
\end{abstract}

Nos últimos tempos, a questão das crianças em situação de rua tem chamado a atenção não apenas de estudiosos no assunto, como também de diversos segmentos da sociedade civil, tendo em vista o quadro dramático relacionado a este fenômeno. Não há dúvida de que fatores de toda índoleeconômicos, políticos, sociais, administrativos- contribuíram para gerar este quadro social de âmbito nacional. Uma leitura crítica sobre a situação infanto-juvenil do Brasil nas últimas décadas aponta para o fracasso na execução das políticas de atendimento ao menor, que redundou em um verdadeiro fomento à marginalidade e à exclusão.

Rizzini e Rizzini (1992) analisaram uma coletânea de estudos realizados ao longo da década de 1980 sobre a situação de crianças e adolescentes no Brasil e concluíram que o crescente número de meninos de rua foi uma conseqüência imediata da política nacional de priorização do crescimento econômico, em detrimento do bem-estar da população. De acordo com os estudos analisados, tal fenômeno deu-se pela necessidade destas crianças gerarem

${ }^{1}$ Endereço para correspondência: Universidade de Brasília, Instituto de Psicologia, Departamento de Psicologia Clínica, Campus Universitário Darcy Ribeiro, Caixa Postal 04500, 70910 900, Brasília, DF.E-mail: inesgand@unb.br/ fatsudbr@unb.br renda para contribuir no orçamento familiar, estando diretamente associado ao processo de empobrecimento do país. A população de meninos de rua atinge proporções de notável visibilidade nos grandes centros urbanos do país, apresentando grandes semelhanças interestaduais, revelando a gravidade do fenômeno de âmbito nacional. Por sua vez, as pesquisas mostraram que a maioria dessas crianças e adolescentes era do sexo masculino; a faixa etária variava dos 7 aos 17 anos, sendo predominante aos 9; a maioria era de pardos e negros e as famílias das crianças eram oriundas de favelas das periferias das grandes cidades.

Os estudos também revelaram que nessa população existe uma diferença entre dois grupos: os que moram nas ruas e os que passam os dias nas ruas. Lusk e Mason (1993), com base em uma pesquisa junto a 113 crianças nas ruas do Rio de Janeiro, distinguem quatro grupos de meninos e meninas de e $n a$ rua: trabalhadores de rua com base familiar $(20 \%)$, trabalhadores de rua independentes $(51 \%)$, crianças de rua (15\%) e crianças de famílias de rua (14\%). Lucchini (1988a) compreende o tema da transição de uma categoria a outra por meio de um modelo, no qual, quanto maior o contato da criança com os adultos responsáveis, menor a permanência 
na rua e vice-versa. $\mathrm{O}$ autor considera a influência de cinco tipos de fatores: biológicos, familiares, relativos à rua, relativos ao espaço urbano e macroscópicos ou sóciopolítico-econômico. Em suma, o autor afirma que todos estes fatores são interdependentes e permitem diversas combinações, acelerando ou refreando a transformação da criança na rua em criança de rua.

A análise dos resultados de um estudo realizado por Alves (1992) com 128 meninos de rua de Goiânia indicou a conjugação de três ordens de fatores na "produção de menino de rua": os sócio-econômicos, os familiares e os individuais. Tal estudo revelou que cerca de um quinto dos menores de rua nunca conviveu com o pai, sendo a imagem do mesmo a de uma pessoa despreparada e impotente para lidar com as dificuldades da vida e as responsabilidades frente à família; marcada por um distanciamento afetivo e se constituindo em um modelo de identificação inadequado para os filhos. Além disto, o estudo confirma que a desqualificação da figura paterna como modelo de identificação representa um fator de risco para a marginalidade.

Quanto às estratégias de sobrevivência, a literatura tem mostrado que algumas crianças de rua lançam mão de outros recursos, além do trabalho, para garantir seu sustento. São as denominadas atividades "marginais" e se dividem em dois grupos: as infratoras (furto, roubo, prostituição e tráfico de drogas) e as não-infratoras (mendicância, perambulância). Porém, apesar de o menino de rua ser freqüentemente associado à toxicodependência e à delinqüência (Lucchini, 1988b), os dados da literatura (Rizzini \& Rizzini, 1992) mostram que o número de menores envolvidos nestas "atividades marginais" é bastante inferior ao número de meninos de rua que não estão envolvidos nessas atividades e que constituem o grupo de menores trabalhadores. Lucchini (1988b) considera o uso de inalantes na população de meninos de rua do Brasil como parte integrante de seu estilo de vida. $\mathrm{O}$ autor acredita que o uso de droga nesta população pode estar ligado ao tema da identidade coletiva e pode ser uma condição para que a criança seja aceita pelo grupo. Seus estudos revelam que o padrão de consumo de drogas entre os meninos de rua difere enormemente das toxicomanias típicas, não devendo ser banalizado nem tampouco exagerado, visto que a procura e o consumo da droga não monopolizam todas as energias e competências das crianças de rua.

Diante deste quadro de abandono e negligência, a medida de internação surgiu como uma tentativa de resolução para esta grave situação na qual se encontravam as crianças e adolescentes em situação de rua. Porém, não resta dúvida de que tal medida acarreta prejuízos no seu desenvolvimento psicossocial. Estudos clássicos - em hospitais e orfanatos (Bowlby, 1981; Spitz, 1965) - indicam os efeitos negativos advindos da prática da institucionalização, por força da privação sensorial e afetiva dos cuidados maternos, que resultam na perda do vínculo afetivo. Goffman (1974) descreveu os estigmas sofridos pelo indivíduo submetido à institucionalização que culminam na despersonificação do ego. A partir destas construções teóricas, surgiram inúmeros estudos em ambientes institucionais diversos, destacando os comprometimentos psicológicos e sociais dos sujeitos confinados em instituições. Diversos foram os trabalhos realizados sobre a institucionalização de crianças e adolescentes, sobretudo nos domínios da FEBEM (Almeida, 1985; Altoé, 1985, 1990, 1993; Blanques, 1988; Guirado, 1980, 1986; Kominsky, 1991; Marin, 1988; Rizzini, 1985; Rizzini \& Rizzini, 1992; Vilhena, 1989; Violante, 1982) e instituições governamentais para menores infratores (Baumkarten, 1992; Gomide, 1990; Mendez, 1993; Sudbrack, 1982).

A prevalência da condição marginal e os paradoxos vividos pelas crianças e jovens marginalizados parecem exacerbados na experiência da institucionalização. A institucionalização de menores infratores oferece, a esta clientela, uma verdadeira "carreira de delinqüente", expondoos a toda sorte de riscos e violências nunca antes vividos. Endossam esta afirmação as pesquisas realizadas por Sudbrack (1982), Gomide (1990) e Arruda (1983). E, ainda, ao sair da instituição - onde os níveis de degradação e violência chegam a ultrapassar os das ruas -, o sujeito está certo de que é intrinsecamente criminoso e sempre culpado, não the restando outra saída que não seja sua inserção na sociedade pela via da marginalidade (Queiroz, 1984).

A situação dos meninos de rua denunciada pelas pesquisas da década de 1980 passou a encontrar eco na sociedade, principalmente por dois motivos: 1) reconhecimento de que as crianças abandonadas não eram, na realidade, abandonadas, pois elas tinham familia; e 2) constatação de que estas crianças constituíam um número significativo, já que metade da população infantil enquadra-se na categoria de abandonadas. A revelação e a compreensão deste fenômeno possibilitaram uma conscientização crescente da questão por parte da sociedade que, a partir de um esforço inédito de vários de seus segmentos, iniciou uma mobilização que culminou na criação do Estatuto da Criança e do Adolescente (ECA). As principais inovações do novo estatuto foram os avanços na explicitação e na clarificação dos direitos e garantias das crianças e adolescentes, passando a considerá-los como seres humanos em desenvolvimento, portanto dignos de proteção especial sob a égide da família, da sociedade e do Estado.

Quanto ao funcionamento de instituições para crianças e adolescentes, o Estatuto levou em consideração todos os aspectos falhos da medida de internação denunciados nos estudos sobre esta prática nas últimas décadas, constituindo, deste modo, um instrumental jurídico que se propunha a acabar com a perspectiva de enclausuramento e despersonificação 
da clientela assistida pelas instituições. Resta, ainda, o maior desafio por parte das instituições diante desta nova perspectiva e, por sua parte, cabe à sociedade civil e ao Estado a tarefa peremptória de vigilância e observância do cumprimento da nova lei por parte das instituições. As críticas à institucionalização redundaram fatalmente no movimento de desinstitucionalização e na abolição da medida de internação indiscriminada de crianças e adolescentes, bem como na adoção de uma nova alternativa de acolhimento destes em meio aberto. Ainda que esta seja uma alternativa factúvel, permanece a questão: que modelo de atuação inspirará tal prática? $\mathrm{E}$, ainda, que modelo de instituição realmente oferece as condições necessárias ao pleno desenvolvimento destas crianças, sem competir com suas famílias e sem estigmatizar a sua clientela? Necessário se faz um olhar sistêmico que considere os diferentes protagonistas que contribuem na construção de uma nova metodologia de trabalho que satisfaça a complexidade das situações.

Opresente texto éum recorte de uma dissertação de mestrado inserida em um projeto mais amplo de estudo subsidiado pelo CNPq, sob o título: “Construindo Redes Sociais: Metodologia de Prevenção à Drogadicção de Adolescentes em Familias de Baixa Renda do DF". Trata-se do estudo sociométrico de uma instituição de atendimento a crianças e adolescentes em situação de rua que, pelas peculiaridades de sua atuação, foi aqui definida como alternativa, tendo sido escolhida para estudo pelo fato de atrair os meninos de rua, conseguindo retirá-los da marginalidade. O presente trabalho tem por objetivo identificar e caracterizar os principais elementos da referida instituição responsáveis pela fixação e adesão da clientela ao seu projeto com vistas a oferecer subsídios para a construção de propostas pedagógicas de atendimento a meninos de rua.

Constituem referenciais teóricos norteadores da pesquisa as teorias do funcionamento de grupos, no enfoque da teoria sociométrica de Moreno (Moreno, 1972), utilizando também contribuições da perspectiva da terapia familiar sistêmica.

\section{Método}

\section{Introdução do pesquisador na instituição}

A inclusão das pesquisadoras ocorreu por intermédio da psicóloga do Centro de Desenvolvimento Social - CDS que atendia alguns meninos desta instituição e que fora designada a orientar a instituição na elaboração de seu projeto de trabalho, face às exigências dos órgãos oficiais de execução de assistência do Governo do Distrito Federal - GDF.

Tratava-se de instituição de cunho comunitário-religioso, localizada nas dependências da Casa Paroquial de uma cidadesatélite do Distrito Federal, dirigida pelo padre desta Paróquia, apoiado por uma médica da comunidade. Ambos os dirigentes possuíam estreito vínculo com a instituição a partir da prestação de serviços voluntários a sua clientela. A instituição não apresentava qualquer documento escrito e tampouco possuía registro formal na rede de instituições credenciadas para a execução de medidas sócio-educativas, não fazendo parte dos espaços legitimados para a execução das políticas sociais do Governo do DF.

No período inicial de observação participante foi possível constatar aspectos da metodologia do trabalho da instituição: a) dimensão participativa no estabelecimento de normas e regras, a partir de discussão grupal; b) atribuição de responsabilidade e autonomia aos seus membros; c)designação de tarefas individuais na rotina e quotidiano da instituição; d) acompanhamento sistemático do desempenho escolar e da rotina de vida de cada membro; e) realização de refeições em conjunto; f) negociação das regras institucionais a partir de demanda individual; g) incentivo ao diálogo com os dirigentes; h) liberdade de opção para o ingresso e permanência na instituição; i) manutenção do vínculo com famillia de origem. Para a consecução deste último item apreendeu-se que, após o ingresso do adolescente na instituição, o padre/dirigente realizava contato com a família de origem, a fim de obter seu consentimento para o acolhimento do mesmo e para avaliar as condições em que ocorrera a saída do lar, esclarecendo que sua proposta era de retorno ao convívio familiar.

Destacou-se, dentre as características da instituição, a forma de ingresso à mesma que conferiu uma especificidade à relação desta com a clientela e à relação dos meninos entre si. O primeiro aspecto de destaque é a demanda voluntária de um subgrupo dos garotos que decidiram morar naquele lugar (a igreja) com aquela pessoa (o padre/dirigente), sendo que aí chegaram e se instalaram em grupo. Constatouse basicamente quatro tipos de ingresso à instituição: 1) encaminhados pelos próprios adolescentes; 2 ) encaminhados por familiares e responsáveis; 3) encaminhados pela própria comunidade local; e 4) encaminhados por instituições governamentais. Pode-se considerar que o ingresso nesta instituição deu-se predominantemente por uma procura espontânea da comunidade ou das famílias. Inclusive, a criação da instituição deve-se a uma busca espontânea de um grupo dos próprios meninos de rua.

No que concerne às vivências junto à instituição em estudo, chamou a atenção a natureza das relações da clientela entre si e da clientela com os seus dirigentes. No que tange à instituição, a maioria dos meninos a caracterizava como uma família, atribuindo o papel de pai ao dirigente, o de mãe à pessoa de apoio e o de irmãos aos demais membros. Alguns deles relataram a existência de brigas, descrevendo-as como inerentes a qualquer grupo familiar. A totalidade das crianças e dos adolescentes afirmou gostar de viver na instituição e quase todos mantinham contato esporádico com suas famílias de origem. Em relação à forma como os meninos da instituição achavam que eram percebidos pela comunidade, 
os relatos demonstraram dois tipos de percepções: ou se percebiam vistos como marginais, delinqüentes, usuários de cola, meninos de rua ou como "filhos do padre". Os que alegaram ser vistos de forma negativa atribuíram tal percepção à presença de membros que faziam uso de droga.

Tendo em vista a riqueza das interações observadas nesta instituição, elaborou-se a hipótese de que o êxito da mesma estaria centrado em um modelo de atendimento fundado no investimento sobre as relações afetivas entre seus membros, numa proposta de trabalho que valoriza o funcionamento grupal.

A partir desta hipótese inicial, ficou definido como objetivo da pesquisa: conhecer a dinâmica grupal vigente na instituição, identificando-se a configuração sociométrica do grupo.

As seguintes questões delimitam o objeto de estudo:

1. Como se configuram as relações entre os membros da instituição do ponto de vista de uma leitura da dinâmica grupal (sociométrica)?

2. Como se refletem os aspectos da configuração grupal na proposta pedagógica de atendimento a crianças e adolescentes em situação de rua desenvolvida por esta instituição?

\section{Participantes}

Constituem participantes do estudo a clientela da instituição e os membros da equipe de trabalho. A equipe era constituída de apenas dois dirigentes: um padre e uma médica da comunidade que trabalhavam voluntariamente. A clientela era composta por 20 crianças e adolescentes, sendo que 18 na faixa dos 11 aos 20 anos e apenas 2 participantes eram crianças de 5 e 6 anos de idade. Dos 20 participantes, 6 não estavam freqüentando regularmente a escola na época do estudo. Os 20 participantes - todos do sexo masculino - no momento da coleta de dados estavam residindo na instituição em estudo, situada na casa paroquial.

Como configuração familiar destas crianças e adolescentes predominavam as famílias pluricompostas, com irmãos de paternidades distintas. Ficou constatada, pelas entrevistas individuais com os participantes sobre suas familias, a presença do alcoolismo dos pais ou responsáveis e de atos de violência física em todos os casos.

Quanto à história pregressa da clientela da instituição, mais da metade era de meninos que já moraram na rua, um terço do grupo exercera atividades de trabalho informal nas ruas e apenas dois deles não apresentaram qualquer experiência de vida ou de trabalho nas ruas. Destacam-se ainda, as seguintes características na história dos participantes: experiências de furtos, períodos de permanência em instituição governamental de assistência e consumo de drogas.

\section{Instrumentos e Procedimentos}

A coleta de dados ocorreu em duas etapas: a primeira destinada a conhecer os participantes da pesquisa e a história da instituição - por meio de relatos verbais dos participantes entrevistados individualmente - e a segunda - destinada a avaliar a dimensão grupal - consistiu na realização do teste sociométrico.

A opção pelo teste sociométrico justifica-se pelo fato de o mesmo revelar a "geografia psicológica do grupo" (Dreyfus, 1980) - além de se coadunar com o enfoque pluralista que contempla os aspectos quantitativos e qualitativos na análise das relações interpessoais do grupo (Monteiro, 2002).

A aplicação do teste ocorreu em um encontro de aproximadamente 3 horas de duração e foi realizado em suas modalidades objetiva e perceptual, cumprindo-se as seguintes etapas: a) escolha da atividade ou do critério da escolha, que deve ser consensual pelos elementos do grupo; b) resposta de cada elemento do grupo ao questionário de escolhas de modalidade objetiva, que consiste nas escolhas hierárquicas - positivas, negativas ou neutras - que o participante faz de cada membro do grupo, seguidas das justificativas de cada uma das escolhas; c) respostas de cada elemento do grupo ao questionário de escolhas de modalidade perceptual - o participante diz como acha que será escolhido pelos demais membros do grupo (se de forma positiva, negativa ou neutra) - e o porquê da escolha; d) realização dos sociogramas - que consistem na "síntese gráfica das congruências e incongruências na escolha dos indivíduos" - que devem ser repassados ao grupo visando à clarificação e ao confronto, garantindo "continente para a elaboração individual e grupal" (Gonçalves, Wolff \& Almeida,1988, p. 42).

O critério unanimemente eleito pelos participantes foi a escolha de membros do grupo com o qual gostariam de fazer uma viagem.

\section{Resultados e Discussão}

\section{Configuração sociométrica}

A configuração sociométrica do grupo apresentou predominantemente escolhas positivas (ver Figuras 1 e 2), centradas principalmente na figura do dirigente $(\mathrm{Q})$ e da pessoa de apoio $(\mathrm{P})$. Esta estrutura parece condizente com os relatos dos meninos que afirmavam, em sua totalidade, gostar de viver neste grupo, aceitando as figuras de autoridade ali existentes. Pode-se inferir que a estrutura sociométrica deste grupo assemelha-se à de uma família idealizada, tendo como centro catalizador das escolhas positivas as figuras dos responsáveis. Estes foram as estrelas sociométricas do grupo, ou seja, obtiveram o maior índice de mutualidade, além do mais elevado índice de percepção e de emissão (ver Tabela 1). De acordo com Carvalho (1987, p. 1), "as famílias 'normais' tendem a possuir uma estrela sociométrica claramente definida (normalmente, a mãe), índices de percepção, emissão mais altos, assim como coesão grupal maior". Esta percepção de estar vivendo em familia se repete 
Tabela 1

Mutualidades (M), Incongruências (I), Índice de Percepção (IP), Índice de Emissão (IE) e Índice Télico (IT) dos Membros do Grupo

\begin{tabular}{clllllllllllllllll}
\hline & $A$ & $B$ & $C$ & $D$ & $E$ & $F$ & $G$ & $H$ & $I$ & $J$ & $L$ & $M$ & $N$ & $O$ & $P$ & $Q$ & $R$ \\
\hline$M$ & 7 & 8 & 5 & 4 & 13 & 8 & 5 & 10 & 9 & 12 & 7 & 6 & 11 & 9 & 13 & 15 & - \\
$I$ & 8 & 7 & 10 & 11 & 2 & 7 & 10 & 5 & 6 & 3 & 8 & 9 & 4 & 6 & 2 & 0 & - \\
$I P \%$ & 60 & 53 & 67 & 80 & 53 & 40 & 47 & 33 & - & 47 & 47 & 33 & 53 & 67 & 60 & 67 & - \\
$I E \%$ & 36 & 36 & 43 & 36 & 64 & 28 & 43 & 64 & - & 64 & 28 & 50 & 57 & 50 & 100 & 93 & - \\
$I T \%$ & 48 & 44,5 & 55 & 58 & 58,5 & 34 & 45 & 48,5 & - & 55,5 & 37,5 & 41,5 & 55 & 58,5 & 80 & 80 & - \\
\hline
\end{tabular}

Índice Télico Grupal: 53,3\%

Sociograma de Mutualidades

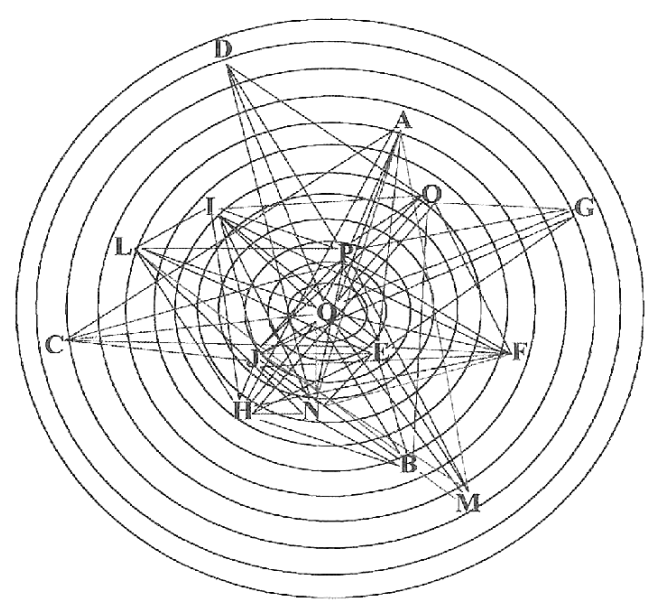

Legenda:

$\begin{array}{llll}\text { Q-Padre Queiroz } & \text { N-Nilo } & \text { F-Fábio } & \text { M-Mauro } \\ \text { P-Paula } & \text { H-Hélo } & \text { B-Bruno } & \text { C-Carlos } \\ \text { E-Ehis } & \text { I-Ismael } & \text { A-Artur } & \text { G-Gabriel } \\ \text { J-José } & \text { O-Osmar } & \text { L-Lauro } & \text { D-Daniel }\end{array}$

Figura 1. Sociograma de mutualidades.

nos depoimentos verbais dos garotos, o que reforça os achados do teste sociométrico. As formas como são construídas as normas de funcionamento da instituição nos remete, igualmente, a uma concepção de família: os dirigentes apresentaram ótimo índice télico, sugerindo identificação com seus papéis e denotando vinculação adequada com seus membros. A dificuldade encontrada em ambos, em hierarquizar suas escolhas, não é muito diferente da atitude dos pais que se recusam a admitir preferências entre os seus filhos.

Cabe ressaltar o fato de que o segundo elemento de maior escolhas positivas do grupo, (D), foi um adolescente que se destacava por uma preocupação excessiva com sua imagem física e estética: roupas de marca, físico alinhado, cabelo na moda, etc. Esta identificação maciça dos meninos com este garoto pode ser denotativo de um movimento dos
Sociograma de Incongruências
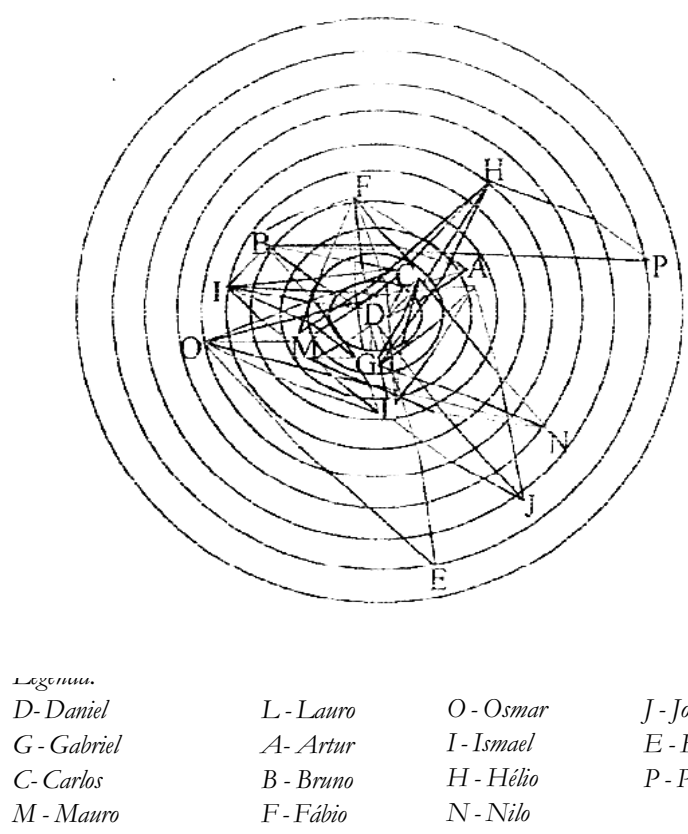

$$
\begin{aligned}
& \text { L-Lauro } \\
& \text { A-Artur } \\
& \text { B-Bruno } \\
& \text { F- Fábio }
\end{aligned}
$$$$
\begin{aligned}
& \text { O-Osmar } \\
& \text { I-Ismael } \\
& H \text { - Hélio } \\
& \text { N-Nilo }
\end{aligned}
$$

J-José

$$
\text { E-Elvis }
$$$$
\text { P - Paulo }
$$

Figura 2. Sociograma de incongruências.

participantes rumo à incorporação do estereótipo do padrão burguês vigente, enquanto estratégia para serem aceitos pela sociedade. Este aspecto do consumismo vem aparecendo em estudos mais recentes nos quais vimos constatando que parcela significativa dos adolescentes em conflito com a lei, sob medida sócio-educativa no Distrito Federal apresenta como justificativas e motivação para a prática de furtos suas prementes necessidades consumistas, dentre estas, vestirem roupas e calçados de marca.

Por seu turno, o menos popular no teste, (R), foi também o mais rejeitado nos depoimentos verbais. Este adolescente - que se recusou a responder ao teste, embora tenha participado de sua execução - era visto como antítese do anterior, pois reunia atributos condenados pelas normas sociais: uso de drogas, envolvimento em furtos e brigas, descuido com a aparência física, linguagem e gírias próprias 
da cultura marginal, etc. Este adolescente comportou-se como receptáculo das tensões negativas do grupo, sugerindo projeções de conflitos entre seus membros. Neste sentido, os dois tipos de dados coletados (resultados do teste e relatos verbais) apresentaram resultados consonantes, sugerindo a exclusão deste membro do grupo porque o mesmo representava do estereótipo negativo do qual queriam se livrar.

Constata-se a repetição no contexto da instituição do mesmo padrão excludente existente na sociedade mais ampla no sentido de rechaçar os usuários de drogas, identificados com o padrão de conduta e de aparência marginal. Esta reflexão sobre a ressonância do comportamento do abuso de drogas na exclusão pelos próprios pares de condição social desfavorecida constitui objeto de pesquisas anteriores. Definimos o processo de dupla exclusão relativo ao rechaço no próprio contexto de origem, sofrido pelos jovens de contextos desfavorecidos quando se tornam dependentes de drogas. Neste sentido, entendemos que o consumo abusivo de drogas é, ao mesmo tempo, gerado pela exclusão e gerador de exclusão. Se, por um lado, consumir drogas relaciona-se às condições precárias de vida destas crianças e adolescentes em situação de rua, por outro, a dependência de drogas especialmente da merla e do crack, na realidade do Distrito Federal, são nítidos fatores de exclusão no contexto das próprias gangues de rua e das comunidades de baixa renda (Sudbrack, 1996).

\section{A proposta pedagógica da instituição}

Apesar de seu caráter filantrópico e voluntário e da falta de uma proposta pedagógica formalizada, a instituição revelou possuir uma linha de ação com princípios educativos e valores que a sustentam, sobre os quais discorremos, a seguir.

A partir da análise das relações afetivas configuradas no convívio grupal dos membros da instituição, evidenciam-se quatro elementos que entendemos como eixos estruturantes da metodologia desenvolvida pela instituição em estudo, a saber:

a) A escolha sociométrica: as redes sociais como critério de seleção da clientela

As bases da formação do grupo obedeceram a um critério sociométrico, tendo em vista que proporção significativa dos sujeitos participou da decisão de ingresso no mesmo, a partir de suas vinculações prévias e espontâneas com os pares. Por sua vez, a adesão dos demais membros à instituição também se deu por critério sociométrico, na medida em que têm opção de fazer ou não parte daquele grupo. Neste sentido, a estrutura das relações e dos vínculos grupais ganha força expressiva, indo ao encontro do ideal de Moreno sobre a construção social de grupos - até mesmo familiares - a partir do critério sociométrico. O autor acreditava ser possível a construção de um verdadeiro "lar psicológico" (Deyfrus, 1980), a partir do aglutinamento das vertentes afetivas dos membros de uma comunidade. Esta é uma característica sui generis da instituição que não pode ser desprezada quando se tem conhecimento de que, de um modo geral, as instituições de atendimento a crianças e adolescentes não se constróem por iniciativa dos mesmos, nem sobre bases sociométricas. Observa-se nas práticas institucionais vigentes uma tendência a não considerar as redes sociais entre os pares como potencial positivo a ser resgatado na proposta pedagógica. Ao contrário, é mais freqüente que se procure separar os grupos, sendo a convivência com os pares, percebida como nociva e não como um recurso positivo a ser otimizado. Este resultado deu origem e nos remete ao trabalho mais recentemente desenvolvido por uma das autoras (Carreteiro \& Sudbrack, 1999; Sudbrack, 1996, 1998, 2000), definindo as redes sociais enquanto uma nova metodologia de prevenção à marginalização e à drogadição entre adolescentes de famílias de baixa renda, em situação de risco psicossocial.

Precisamos reconhecer a importância das redes de pares que, freqüentemente, constitui a rede primária desta população de crianças em situação de rua, em substituição à familia. A exemplo do que se constatou na instituição em estudo, consideramos que a preservação das redes sociais revela-se importante enquanto critério de seleção da clientela nas instituições de atendimento a crianças e adolescentes em situação de rua.

b) O sistema educativo: a afinidade e a integração entre os dirigentes da instituição

Por seu turno, os dirigentes da instituição também se agruparam com base nas preferências de ambos, tanto em relação à afinidade entre si mesmos, como entre estes e a clientela da instituição. A consonância de seus objetivos da qual resulta a integração entre os dirigentes da instituição, bem como a afinidade destes com seu público-alvo aparecem, neste estudo, como elementos fundamentais ao sucesso da intervenção em questão. Mais uma vez, a reestruturação da coletividade sobre o critério das redes sociais ganha força na abrangência do universo dos recursos humanos. É evidente a necessidade de uma consistência ideológica e afetiva na composição das equipes no trabalho junto a crianças e adolescentes, tendo em vista que, não apenas os educadores mas, sobretudo, a natureza de suas relações, se configuram como modelos interativos captados e assimilados como referências identificatórias pela clientela.

A literatura específica sobre as instituições de atendimento a crianças e adolescentes aponta que o modelo ditado pelas relações burocráticas de trabalho - onde o funcionário público é treinado 
a prestar atendimento - é isento de afetividade, reproduzindo a desigualdade e impossibilitando a construção de vínculos humanos (Kominsky, 1991). Portanto, este modelo de interação perpetua a condição de abandono das crianças institucionalizadas.

O estatuto sociométrico do grupo conferiu ao mesmo uma estrutura coesa, na medida em que ao líder (o dirigente da instituição) correspondeu o destaque enquanto estrela sociométrica. As instituições a cargo dos cuidados de crianças e adolescentes, com as características descritas pela literatura, provavelmente não concentrariam suas preferências em seu dirigente e dificilmente este seria a estrela sociométrica do grupo. Necessário se faz realizar novos estudos desta natureza que possam aprofundar e melhor delinear esta hipótese. Temos, no entanto, fatos concretos que constituem dados de realidade relativos à freqüência de motins e fugas nas instituições de atendimento a esta clientela que falam por si só. A insubordinação da clientela de instituições totais aos comandos de seus dirigentes pode ser entendida como não-aceitação do papel em que estes se colocam para seus assistidos. A revolta é, portanto, endereçada ao papel de autoridade negativa assumida pelo dirigente, na medida em que este se coloca como "padrasto" e não como pai. Por sua vez, o papel negativo em que a clientela é colocada, a partir do estigma que lhe é atribuído, constitui elemento complementar que contribui para a formação de um circuito repetitivo de desqualificações entre os dirigentes e a clientela. c) Viver em familia: um projeto compartilhado pela instituição e pela clientela

Ficou constatado que a expectativa dos participantes, ao buscarem a instituição, era a possibilidade de viver em família. Considerando-se que todos os participantes tinham famílias de origem, esta busca coloca-se como uma alternativa ao modelo familiar originário. A ênfase dada ao papel do padre/ dirigente no lugar do pai - tanto nas histórias de vivências na instituição, como nos resultados do teste sociométrico - e os relatos de vínculos conflitivos com o pai original nos levam à hipótese de que, em última instância, os participantes buscavam um novo modelo de pai ou a correspondência com o modelo de pai idealizado. Reponta aqui, novamente, o ideal moreniano muitas vezes taxado de utópico ou messiânico - da reconstrução da sociedade pautada em escolhas sociométricas.

No que tange à referência afetiva da figura feminina de apoio, esta revela-se enquanto prolongamento da figura materna real e, ainda, preservada na vida dos sujeitos. Por sua vez, a preocupação da dirigente da instituição, em se oferecer como apoio, procurando não competir com as mães dos participantes representa uma tranqüilidade para os mesmos. Esta possível relação de aliança e de complementaridade com as mães evita o surgimento de sentimentos de culpa por estarem traindo a verdadeira mãe. Destacamos aqui a importância de se respeitar o sentimento de lealdade à família de origem, muito presente nestas crianças, em especial no que se refere à mãe. Consideramos que a atitude da dirigente, de valorização e respeito à lealdade dos meninos face aos seus vínculos familiares de origem, permitiu a aceitação de sua pessoa como uma referência afetiva materna complementar para eles. Neste sentido, este estudo corrobora trabalhos anteriores apontados pela literatura que revelam os prejuízos para as crianças e adolescentes advindos da desqualificação e da competição com suas famílias de origem. Daí, pode-se supor que a internação em instituição, se for inspirada no modelo do resgate de uma convivência familiar alternativa, pode ser estruturante e não, necessariamente, prejudicial. Encontramos neste estudo um exemplo de que é possível um atendimento institucional que recupere a noção positiva de família e que qualifique a família de origem como competente (Ausloos, 1995), dimensão essencial à formação dos sujeitos.

Guirado (1986) afirma que faz diferença para quem é cuidado ocupar o papel de filho ou de assistido nas representações do cuidador. Portanto, está no papel explícito e afetivo em que se coloca o cuidador, e na sua coerência de não-competição com as referências familiares dos sujeitos, o ideal na formação de qualquer modelo institucional. Assim sendo, coloca-se aqui a necessidade da consonância entre a equipe de agentes institucionais e a mãe dos sujeitos assistidos, de forma que ambos se complementem na tarefa de educar e oferecer uma estrutura afetiva continente à criança.

O presente estudo traz à luz como aspecto fundamental da efetividade desta "família/instituição" ou "instituição/ familia" a sua proposta de não se colocar em competição, ou em substituição ou, ainda, em desqualificação das famílias, mas em sua complementaridade e na preservação dos vínculos afetivos com a família de origem das crianças e adolescentes que acolhe e abriga.

d) A busca do pai: A presença da figura masculina como autoridade

Tendo em vista que as instituições raramente estão estruturadas na fórmula triangular típica: pai-mãe-filho (Marin, 1988), principalmente por causa da ausência constante de figuras masculinas nas equipes, repete-se no modelo institucional a mesma carência vivida pelos sujeitos no modelo da familia de origem. Um dos resultados desta investigação referese, exatamente, a esta dimensão, apontando para a importância da presença de figuras masculinas em papéis positivos de responsáveis e/ou dirigentes.

O dirigente da instituição estudada assumia claramente seu propósito de desempenhar o papel de pai para a clientela. 
Ao assumir plenamente este contra-papel, o padre/dirigente, aceitando a função de pai, contribui no desempenho desejado do papel de filho de seus assistidos.

A demanda da busca do pai encontrada na presente pesquisa vem ao encontro de trabalhos anteriores, enquanto dimensão importante em adolescentes que se envolvem na prática de infrações (Sudbrack, 1987). Este processo denominado da falta do pai à busca da lei remete à compreensão do significado da passagem ao ato delinqüente no contexto familiar e institucional (Sudbrack, 1992).

No presente estudo, pudemos confrontar esta tendência de busca do pai ou de uma figura de autoridade entre meninos de rua, ainda no início de sua trajetória rumo à marginalização. O conflito evidenciado situa-se exatamente no confronto entre a necessidade de um pai e a condição real de suas histórias de vida em que seus progenitores aparecem como figuras desqualificadas e omissas no exercício da paternidade. Como respeitar a figura do pai quando esta está, invariavelmente, associada à degradação humana, ao vício e à violência?

A condição real de suas histórias de vida revela o pai como figura desqualificada e omissa no exercício da paternidade, como ilustram as situações de alguns participantes:

O pai de J. bebia muito e brigava com a mãe. Um dia, ela bateu um martelo na cabeça dele, pegou seus dois irmãos mais novos e viajou. Ele e o irmão mais velho ficaram com o pai e sempre apanhavam dele, que lhes batia com facão. " $L a ́$ no assentamento é ruim pra caramba" porque apanham do pai. Depois que vieram para cá, não voltaram mais ao assentamento. J. disse que não sente falta de casa. Gosta da mãe. Não sente falta do pai porque apanhava muito.

A. disse que sua família é "escrota, não tinha nada, tudo era mal organiżado, não tinba muita união, tinha muita briga”, sempre brigou com os irmãos. A. "tinha a mania de olhar muito revoltado para a cara da mãe". A. não conheceu seu pai. A mãe conta que ele mexia muito com droga e cachaça, "ele era louco". Numa época, brigava direto com a mãe e a espancava na rua. Foi daí que ela ficou com um problema de nervo na perna e não conseguiu mais andar normalmente, nem consegue andar sozinha. A mãe fugiu do pai e foi cuidar da vida.

Destaca-se que as necessidades de expressar o respeito pela figura de pai e a de viver plenamente o papel de filho, estariam determinando a escolha do padre/dirigente para viver este papel tão importante e, ao mesmo tempo, tão inacessível na história familiar dos participantes. Pode-se inferir que esta busca de um modelo substituto do pai da família de origem opera no sujeito uma reestruturação de sua matriz de identidade, tendo em vista que, em sua matriz originária, o papel de pai não configurava como um modelo possível e/ou desejável de identificação.

O estudo aponta que os participantes estão em um processo de resgate dos limites, normas e referências de autoridade não encontrados em suas histórias familiares. Este desejo se expressa, por uma demanda de regras de convivência e de obediência, a uma autoridade que delegam ao dirigente da instituição, como podemos constatar nas seguintes vinhetas:

Para B. o Padre é um pai. "Se existisse Deus no mundo, esse Deus é o Padre. Não existe ninguém como o Padre". "Os meninos de lá, quando pedem alguma coisa para o Padre e ele não dá logo, ficam de cara feid'. Ele não, se o Padre puder dar, bem, senão, tudo bem.

A. contou que o Padre disse que os considerava como filhos e perguntou porque eles não o chamavam de pai. Eles não tinham coragem. "Quando muito, chamavam de velho. Lá é como uma familia e os meninos são como irmãos". O relacionamento entre os meninos de lá é legal. Quando um precisa, um ajuda o outro. Mas, lá também tem muita briga. Acha que se não se desse tanta liberdade, não teria briga.

O presente estudo corrobora com a literatura relativa à constatação de que para grande parte da população dos meninos de rua a figura do pai é a de um homem frágil e ausente (Alves, 1992) - portanto, de um modelo inadequado de identificação.

Diante da constatação de que é exatamente esta figura de autoridade masculina que os sujeitos estão buscando na instituição em questão, entendemos que a proposta do padre/ dirigente situa-se na dimensão de estar assumindo um do níveis da paternidade, no caso a paternidade social (Sudbrack, 1997) destas crianças e jovens. Por sua vez, esta disponibilidade do padre/dirigente coloca-se em sábia consonância com a demanda dos sujeitos em busca de uma figura positiva de autoridade.

Nos referimos, aqui, à função paterna em sua dimensão simbólica, sendo que a mesma está intrinsecamente implicada com o exercício da paternidade a ser considerado em diferentes níveis, a saber: 1) o pai biológico; 2) o pai legal; 3) o pai social; e 4) o nome do pai ou o pai simbólico (Sudbrack, 1992).

No contexto da instituição em estudo, podemos considerar que o padre/dirigente estaria assumindo a paternidade social das crianças e adolescentes, a partir da qual poderia ser possível uma reconstrução subjetiva em torno da figura paterna (pai simbólico), vivida e introjetada como positiva, protetora e valorizada como modelo de autoridade. 


\section{Conclusão}

É evidente que a solução ideal para a questão dos meninos em situação de rua culminaria em seu retorno à convivência com seu núcleo familiar de modo harmonioso. Nas práticas institucionais esta perspectiva se confronta com as contradições não apenas dos modelos técnicos de atendimento, mas também, com a questão estrutural mais ampla que impede tanto os filhos como suas famílias como um todo de viverem a plena cidadania.

Por outro lado, questiona-se: de que valeria viabilizar a convivência dos meninos com suas famílias, se o modelo social e político vigente - construído sobre os alicerces sócio-econômicos marginalizantes - não oferece retaguardas para sair desta situação inicial que engendrou a atual condição? Como oferecer a possibilidade de reconstrução dos vínculos familiares se o que os remete à rua é justamente a falta de uma estrutura continente?

Os resultados desta pesquisa identificando elementos alicerces de uma proposta técnica de atendimento a meninos em situação de rua mostram-se consoantes às determinações sobre o funcionamento das instituições de atendimento a crianças e adolescentes do ECA. Entende-se que o estatuto apresenta bases legais para um trabalho com ênfase no papel paterno nas quais prevalecem também os limites e as normas mormente exercidas pela figura paterna. Neste sentido, Canotilho (1982) examina comparativamente os alicerces em que se constróem as leis que regem os países desenvolvidos e os países em desenvolvimento, concluindo que nos primeiros, a base constitucional delineada expõe um caráter paternal no sentido de que incentiva seus cidadãos a todo tipo de liberdade econômica, política e social. Já nestes últimos, as constituições retratam um modelo materno, na medida em que assumem um aspecto assistencialista, à base da convicção de que o quadro geral de precariedade impõe este tipo de conduta estatal.

Podemos relacionar os achados deste estudo com trabalhos anteriores (Sudbrack, 1987) no sentido de que continua prevalecendo entre os meninos em situação de rua o desejo de encontrar um sistema de valores onde exista uma hierarquia de poder e de autoridade, diferenciada daquela apenas ditada pelos pares da rua, que delimite suas ações e que os situe dentro de um contexto de ordem e respeito.

Mesmo reconhecendo que o trabalho institucional é limitado face ao contexto social mais amplo de exclusão, entendemos que novos caminhos se abrem na medida em que introduzirmos no atendimento a meninos de rua as quatro dimensões encontradas na proposta de atendimento da instituição estudada, legitimadas por suas próprias vivências e emergentes em suas próprias demandas.
Para concluir, destacamos que, face aos tantos desafios e questões que permeiam a assistência aos meninos em situação de rua, alguns parâmetros de como trabalhar nesta área já se fazem claros, destacando-se o que se consolida com este estudo: a importância do resgate da convivência familiar e da rede primária afetiva que permita a construção de novos modelos de referência da autoridade e novos padrões de relações afetivas e sociais.

\section{Referências}

Almeida, S. F. C.(1985). Formação e funções do pessoal responsável pela aplicação dos programas de prevenção e de reeducação de menores marginalizados, no Brasil. Psicologia Argumento, 5, 29-44.

Altoé, S. (1985). Os processos disciplinares nos internatos de menores. Espaço Cadernos US: O Menor em Debate, 11, 39-51.

Altoé, S. (1990). Infâncias perdidas: O cotidiano nos internatos-prisão. Rio de Janeiro: Xenon.

Altoé, S. (1993). Do internato à prisão: Quem são os presidiários egressos de estabelecimentos de assistência à criança e ao adolescente. Em I. Rizzini (Org.), A criança no Brasil hoje: Desafiopara o terceiro milênio (pp. 213-229). Rio de Janeiro: Universitária Santa Úrsula.

Alves, A. J. (1992). Meninos de rua e meninos da rua: Estrutura e dinâmica familiar. Em A. Fausto \& R. Cervini (Orgs.), O trabalho e a rua: Crianças e adolescentes no Brasil urbano dos anos 80 (pp. 117-132). São Paulo: Cortez, UNICEF, FLACSO, CBIA.

Arruda, R. S. V. (1983). Pequenos bandidos. São Paulo: Gobal.

Ausloos, G. (1995). La compétence des familles: Temps, cahos et processus. Paris, ERÈS.

Baumkarten, S. (1992). Função paradoxal da delinqüência juvenil no contexto familiar e social. Dissertação de Mestrado não-publicada, Curso de Pós-Graduação em Psicologia Clínica, Universidade de Brasilia. Brasília, DF.

Blanques, A. M. (1988). Eu não tenho nada pra falar: Depoimento sobre a vivência de uma morte simbólica ou história da experiência como psicóloga da FEBEM-SP. Dissertação de Mestrado não-publicada, Curso de Pós-Graduação em Psicologia Clínica, Universidade de São Paulo. São Paulo, SP.

Bowlby, J. (1981). Cuidados maternos e saúde mental. São Paulo: Martins Fontes.

Canotilho, J. J. (1982). Constituição dirigente e vinculação do legislador: Contributo para a compreensão das normas constitucionais programáticas. Portugal: Coimbra.

Carreteiro, T. C. \& Sudbrack, M. F. O. (1999). Drogues, jeunesse et exclusion sociale au Brésil. Em T. Ragi (Org.), Agora Débats (pp. 94-106). Paris:Institut National de la Jeunesse et de l'Education Populaire.

Carvalho, E. R .S. (1987). A estrutura sociométrica de famílias alcoólatras: Um estudo exploratório. Dissertação de Mestrado não-publicada, Curso de Pós-Graduação em Psicologia Clínica, Universidade de Brasilia. Brasília, DF.

Dreyfus, C. (1980). Psicoterapias de grupo. Lisboa/São Paulo: Verbo.

Goffman, E. (1974). Manicômios, prisões e conventos. São Paulo: Perspectiva.

Gomide, P. (1990). Menor infrator: A caminho de um novo tempo. Curitiba: Juruá.

Gonçalves, C. S., Wolff, J. R. \& Almeida, W. C. (1988). Lições de psicodrama: Introdução ao pensamento de J. L. Moreno. São Paulo: Ágora.

Guirado, M. (1980). A criança e a FEBEM. São Paulo: Perspectiva.

Guirado, M. (1986). Instituiçoees e relações afetivas: O vínculo com o abandono. São Paulo: Summus.

Kominsky, E. V. (1991). Internados: Os filhos do Estado padrasto. Em J. S. Martins. (Org.), O massacre dos inocentes: A criança sem infância no Brasil(pp. 155180). São Paulo: Hucitec.

Lucchini, R. (1988a). Identité et survie: Les enfants et la rue au Brèsil. Working Papers, 147. Suisse: Université de Fribourg.

Lucchini, R. (1988b). Enfants et drogues: Consommation et toxicodependance. Working Papers, 118. Suisse: Université de Fribourg. 
Lusk, M. W. \& Mason, D. T. (1993). Meninos e meninas “de rua" no Rio de Janeiro. Em I. Rizzini (Org.), A criança no Brasil hoje: Desafio para o terceiro milênio (pp. 153-171). Rio de Janeiro: Universitária Santa Úrsula.

Marin, I. S. K. (1988). FEBEM, família e identidade: O lugar do outro. São Paulo: Babel Cultural.

Mendez, E. G. (1993). Adolescentes infratores graves. Em I. Rizzini (Org.), $A$ criança no Brasil hoje: Desafio para o terceiro milênio (pp. 231-248). Rio de Janeiro: Universitária Santa Úrsula.

Monteiro, A. M. (2002). Sociometria diádica: Considerações teórico-práticas. Tese de Doutorado não-publicada, Curso de Pós-Graduação em Psicologia Clínica, Universidade de Brasília. Brasília, DF.

Moreno, J. L. (1972). Fundamentos de la sociometría. Buenos Aires: Paidós.

Queiroz, J. J. (1984). O mundo do menor infrator. São Paulo: Cortez.

Rizzini, I. (1985). A internação de crianças em estabelecimentos de menores: Alternativas ou incentivo ao abandono. Espaço Cadernos de Cultura USU: O Menorem Debate, 11, 17-38.

Rizzini, I. \& Rizzini, I. (1992). "Menores" institucionalizados e meninos de rua: Os grandes temas de pesquisa das décadas de 80. Em A. Fausto \& R. Cervini (Orgs.), O trabalhador e a rua: Crianças e adolescentes no Brasil urbano dos anos 80 (pp. 69-89). São Paulo: Cortez, UNICEF, FLACSO, CBIA.

Spitz, R (1965). O primeiro ano de vida: Um estudo psicanalitico do desenvolvimento normal e anômalo das relações objetais. São Paulo: Martins Fontes.

Sudbrack, M. F. O. (1982). A trajetória da criança marginalizada rumo à delinqüência. Revista da Sociedade de Psicologia do Rio Grande do Sul, 9, 5-12.

Sudbrack, M. F. O. (1987). La dimension familiale dans la delinquance des jeunes: La fonction paternelle dans une lecture du passage à l'acte. Tese de Doutorado em Psicologia não-publicada, Université de Paris XIII. Paris, França.
Sudbrack, M. F. O. (1992). Da falta do pai à busca da lei: O significado da passagem ao ato delinqüente no contexto familiar e institucional. Psicologia: Teoria e Pesquisa, Suplemento, 8, 447-457.

Sudbrack, M. F. O.(1996). Construindo redes sociais: Metodologia de prevenção à drogadição e à marginalização de adolescentes de famílias de baixa-renda. Em R.M. Macedo (Org.), Família e Comunidade: Coletâneas da ANPEPP, 2, 87-113.

Sudbrack, M. F. O. (1998). Situações de risco à drogadição entre crianças e adolescentes no contexto de baixa renda: Os paradoxos e as possibilidades da família. Revista SER Social, 3, 219-243.

Sudbrack, M. F. O. (2000). Abordagem comunitária: Uma nova forma de pensar a prevenção do uso indevido de drogas. Em M. F. O. Sudbrack, E. M. F. Seidl \& L. F. Costa (Orgs.), Prevenção do uso indevido de drogas: Diga SIM à Vida, 2, Brasilia: CEAD-UnB e SENAD-SGI-Presidência da República.

Vilhena, M. C. J. (1989). Estudo de alguns aspectos do relacionamento inspetor-menor institucionalizado na FEBEM. Dissertação de Mestrado não-publicada, Curso de Pós-Graduação em Psicologia Escolar e do Desenvolvimento Humano, Universidade de São Paulo. São Paulo, SP.

Violante, M. L. (1982). O dilema do decente malandro. São Paulo: Cortez.

Sobre as autoras

Maria Inês Gandolfo Conceição é Professora Adjunta do Departamento de Psicologia Clínica da Universidade de Brasília. É Coordenadora do Laboratório de Família, Grupos e ComunidadesPCL/UnB. É Doutora em Psicologia.

Maria Fátima Olivier Sudbrack é Professora Titular de Psicologia Clínica da Universidade de Brasília. É Coordenadora do Programa de Estudos e Atenção às Dependências QuímicasPRODEQUI/PCL/UnB. É Doutora em Psicologia e Pós-doutora em Psicossociologia. É Pesquisadora do $\mathrm{CNPq}$ 